\title{
Burden of Co-Infection: A Cost Analysis of Human Immunodeficiency Virus in a Commercially Insured Hepatitis C Virus Population
}

\author{
T. Joseph Mattingly II (D) - Neha S. Pandit - Eberechukwu Onukwugha
}

Received: November 19, 2018 / Published online: March 2, 2019

(C) The Author(s) 2019

\begin{abstract}
Introduction: In patients with hepatitis $C$ virus (HCV), human immunodeficiency virus (HIV) represents a major cause of morbidity and economic burden. Economic evaluations in HIVHCV typically focus on government-sponsored insurance plans rather than a commercially insured cohort. This study evaluated the clinical and economic burden of HIV-HCV co-infection compared with HCV alone in commercially insured patients throughout the United States. Methods: Commercial medical and pharmacy claims from 2007 to 2015 from a 10\% random sample of enrollees within the IQVIA PharMetrics Plus ${ }^{\mathrm{TM}}$ administrative claims database were analyzed. Patients were included based on the presence of a claim with a HCV diagnosis across three separate cross-sectional periods which were created from the full dataset (2007-2009,
\end{abstract}

Enhanced Digital Features To view enhanced digital features for this article go to https://doi.org/10.6084/ m9.figshare.7745429.

T. J. Mattingly II $(\bowtie) \cdot$ N. S. Pandit

Department of Pharmacy Practice and Science, University of Maryland School of Pharmacy,

Baltimore, MD, USA

e-mail: jmattingly@rx.umaryland.edu

E. Onukwugha

Department of Pharmaceutical Health Services

Research, University of Maryland School of

Pharmacy, Baltimore, MD, USA
2010-2012, and 2013-2015). Costs incurred were categorized as emergency department, inpatient, outpatient medical, outpatient pharmacy, and other, based on the claim place of service. Descriptive statistics and proportion of total costs in each group have been reported for all cost categories.

Results: The samples included 22,329 from 2007 to $2009,23,186$ from 2010 to 2012, and 27,288 from 2013 to 2015 . In all three crosssections, HIV-HCV individuals were more likely to be male and carriers of hepatitis $\mathrm{B}$ virus. Pharmacy costs were $\$ 29,368$ in the HCV-only group, compared to $\$ 73,547$ in the HIV-HCV group ( $p<0.0001)$. Pharmacy costs increased as a proportion of total costs for both groups, increasing after 2012 from $41 \%$ to $55 \%$ for HIVHCV and from 19\% to 34\% for HCV-only.

Conclusion: The present study describes the total direct health care costs in HIV-HCV coinfected individuals and HCV-only patients in commercially insured health plans. Spending on pharmacy increased as a proportion of total health care costs in both groups. Further clinical and economic evaluations in HCV and/or HIV populations in the US should consider systemlevel factors related to insurance type when applying to the entire population.

Keywords: Burden-of-illness; Co-infection; Cost-of-illness; Hepatitis C; HIV 


\section{INTRODUCTION}

For individuals infected with hepatitis $C$ virus (HCV), a major cause of morbidity and mortality is a concurrent infection with the human immunodeficiency virus (HIV) [1, 2]. Globally, an estimated 4-5 million people are living with HIV-HCV co-infection [3]. Fortunately, the development of direct-acting antiviral (DAA) therapies has enabled clinicians to effectively cure HCV in both mono- and co-infected patients $[2,4,5]$. In addition to clinical effectiveness, DAA regimens have demonstrated cost-effectiveness in patients with HIV-HCV by avoiding downstream adverse events such as decompensated cirrhosis, liver transplantation, or hepatocellular carcinoma $[2,6]$.

Despite these advances in therapy, many system barriers to HCV treatment still exist, preventing many patients from seeking appropriate therapy [7-9]. These barriers can be especially problematic to patients suffering from HIV-HCV co-infection as many of these patients may have additional challenges, including non-adherence to clinic visits, psychiatric disorders, or issues with substance abuse [10].

Cost-of-illness, or burden-of-illness, studies have been commonly used over the past few decades in health economics to describe spending pertaining to a specific disease or patient population to help inform policy decisions [11]. In general, cost-of-illness studies typically use either a "total cost" or "incremental cost" approach to estimate the cost-of-illness based on the research question under investigation [12]. The total cost approach may focus on the sum of all medical costs or only sum the direct costs related to the disease of interest. The incremental cost approach will identify patients with and without the disease and may utilize statistical techniques (e.g. matched controls, regression, or both) to more accurately attribute a dollar amount to the independent variable (disease) [13]. From a payer perspective, both approaches may be valuable for decision-making, as total cost evaluations help describe the overall spend for the population while the incremental approaches provide a stronger argument for a causal link.
Cost-of-illness evaluations of HCV and HIVHCV typically focus on populations where the government may be the primary payer, as with Medicare, Medicaid, correctional facilities, or within the Department of Veterans Affairs health system [14-17]. The focus on government payer budgets for HIV and HCV treatments may not be transferrable to a commercially insured population. For example, a prospective cohort study comparing 96 co-infected patients to 165 matched HIV patients found that co-infected individuals were more likely to be African American, report alcohol and illicit drug use, and require federal or need-based funding for care (Medicare, Medicaid, and Ryan White) [18]. When co-infection was evaluated in a veteran population in 2016, inpatient costs were driven by psychiatric disease and substance abuse, which the authors acknowledged as a potential confounder due to the higher rates of posttraumatic stress disorder seen in veterans [16]. Demographic and epidemiologic characteristics for HIV-HCV and HCV-only patients on government-sponsored plans may differ significantly, which may have an impact on health resource utilization. The prevalence and total cost estimates from studies in government-sponsored populations may be driven by other system-level factors seen less frequently in a commercially insured population [19]. Aggregating commercial and government insurance claims in the United States (US) may be more meaningful for non-US health systems where a single payer is responsible for the population. This study aims to fill the gap total cost information for the commercially insured population by describing the clinical and economic burden of HIV-HCV co-infection and HCV-only groups in commercially insured patients throughout a national US sample from 2007 to 2015.

\section{METHODS}

\section{Identification of HCV-Only and HIV-HCV Co-Infected Patients}

The data include commercial insurance plans' medical and pharmacy claims from 2007 to 2015 from a 10\% random sample of enrollees 
within the IQVIA PharMetrics Plus ${ }^{\mathrm{TM}}$ administrative claims database. The dataset includes adjudicated medical and pharmacy claims for over 150 million US health plan enrollees after 2006 and are representative of the US commercially insured population (more information regarding the database can be found at http://www.iqvia.com). Patients were eligible for inclusion based on the presence of diagnosis codes in the paid administrative claims. Diagnosis codes were derived from the International Classification of Diseases (ICD) 9th and 10th revisions. In each period, enrollees with a claim with at least $1 \mathrm{HCV}$ and at least $1 \mathrm{HIV}$ diagnosis will be included and categorized as HIV-HCV, while patients with a claim with at least $1 \mathrm{HCV}$ diagnosis but no HIV diagnosis will be included and categorized as HCV-only. Three separate cross-sectional periods were created from the full dataset: 2007-2009, 2010-2012, and 2013-2015. Patients were unique to each time period based on IQVIA's patient identifier, but the same patient could exist across multiple time periods. This article does not contain any studies with human participants or animals performed by any of the authors, and the study protocol was reviewed and approved as "Not Human Subjects Research" by the University of Maryland, Baltimore Institutional Review Board, on May 10, 2018. All subjects in the dataset were de-identified to the research team, as IQVIA's unique patient identifier is not related to other common patient identifiers (names, social security numbers, etc.).

\section{Demographics and Comorbidities}

Other variables described in the cross-sectional periods include age (in years), gender, potential comorbidity cost drivers, other comorbidities, and diagnoses for substance abuse. With HCV, we know from previous studies that advancing liver fibrosis has a significant impact on total costs of the disease [20]. McAdam-Marx et al. used a large dataset to determine the incremental cost per patient per year associated with $\mathrm{HCV}$ by matching $\mathrm{HCV}$ patients with select controls on index date, gender, hospital region, comorbidities for alcoholism, substance abuse,
HIV/AIDS, and a modified Charlson Comorbidity Index, giving us some indication of factors that may drive costs comparisons [21]. Building on prior literature, we have included indicators for cirrhosis, any stage of chronic kidney disease (CKD), hepatitis B virus (HBV), hepatocellular carcinoma (HCC), and history of organ transplant as potential comorbidity cost drivers. Other comorbidities of interest included cardiovascular disease (CVD), diabetes, major depressive disorder (MDD), substance abuse, and schizophrenia. Substance abuse was identified based on the ICD-9/ICD-10 diagnosis of alcohol, cannabis, or opioid abuse.

\section{Cost Measures}

The perspective of this analysis was from the health-sector perspective [22]. We quantified the direct medical costs among patients identified with both HIV-HCV and among patients with HCV-only. Costs incurred were categorized as emergency department, inpatient, outpatient medical, and outpatient pharmacy, other, and unknown, based on the claim place of service reported. All costs were normalized to the last year in each cohort $(2009,2012$, and 2015) by using the Personal Health Care index [23].

\section{Analysis}

Descriptive statistics were calculated for both HIV-HCV and HCV-only groups across all three time periods using SAS v.9.4 (Cary, NC, USA). Variables were compared between each group using Chi-square or Fisher's exact test for categorical data and $t$ test for continuous data, and considered statistically significant at $\alpha=0.05$. The proportion of total costs in each group was calculated for all cost categories. All patients identified in each time period were included in the analysis, and the total number of patients only appearing in a single period was reported.

\section{RESULTS}

The cross-sectional periods included total patient samples of 22,329 from 2007 to 2009, 
23,186 from 2010 to 2012 , and 27,288 from 2013 to 2015. In terms of overlapping with patients appearing in multiple periods, 14,946 (67\%) from 2007 to 2009; 12,263 (53\%); and $20,070(74 \%)$ patients were unique and only appeared in a single period.

In all three cross-sections, HIV-HCV co-infected individuals were more likely to be male and carriers of HBV (Table 1). The prevalence of MDD and schizophrenia was significantly higher in the HIV-HCV groups in 2010-2012. Substance abuse was significantly higher for HIV-HCV for alcohol and opioids in 2007-2009 and for opioids in 2010-2012. Prevalence of liver transplant was statistically higher in the HCV-only group in 2007-2009, but not in the other two time periods. Rates for organ transplant (0.4-1.8\%), cirrhosis (10.6-16.2\%), and HCC (1.6-2.5\%) were similar across both groups during all time periods. Rates for CKD were similar for both groups in 2007-2009 but increased for HIV-HCV patients in 2010-2012 and 2013-2015.

Total costs per patient were higher for HIVHCV patients across all cross-sections (US\$73,547 vs. 29,368 for $2007-2009 ; \$ 86,406$ vs. 34,022 for $2010-2012$; and $\$ 96,703$ vs. $\$ 43,362$ for 2013-2015). The proportion of total costs allocated to inpatient, outpatient, emergency department, pharmacy, other, and unknown categories were stable between the 2007-2009 and 2010-2012 cross-sections (Table 2). Pharmacy costs increased as a total dollar amount and as a proportion of total costs for both groups in 2013-2015, with pharmacy costs increasing $34 \%$ (from $41 \%$ to $55 \%$ ) for HIV-HCV co-infected individuals and 79\% (from 19\% to 34\%) for HCV-only (Fig. 1). For the HIV-HCV groups, pharmacy costs per patient increased from \$36,854/year in 2007-2009 to $\$ 56,688 /$ year in $2013-2015$. For HCV-only, pharmacy costs per patient increased from $\$ 6568 /$ year to $\$ 16,466 /$ year.

\section{DISCUSSION}

This study describes the clinical and economic burden of HIV-HCV co-infection and HCV-only groups in a commercially insured population by dividing the data into three cross-sectional periods to minimize potential misclassification bias and the influence of cost inflation or changes in treatment guidelines within the period. Norton et al. evaluated health care utilization between 96 HIV-HCV and 165 HIV-only clinic patients from 2006 to 2007 to estimate the burden of HCV [18]. While insurance status was not assessed, age and sex demographics were comparable with this study, with mostly male patients between 45 and 52 years of age in the co-infected group [18]. Compared with that study, we found a much lower prevalence of substance abuse and renal disease, but a higher prevalence of diabetes in our HIV-HCV group.

Katrak et al. evaluated health care utilization within a cohort of 335,371 veterans from 1998 to 2009 with either HCV-only, HIV-only, or HIV-HCV co-infection, finding that psychiatric and substance abuse disorders were the predominant drivers of inpatient admissions of all three groups, suggesting a confounder when veterans are included in a cost-of-illness analysis of HCV or HIV [16]. Our study found a lower prevalence of psychiatric co-morbidities including MDD, schizophrenia, or substance abuse in both HCV and HIV-HCV groups compared to previous studies in veterans, Medicaid recipients, or prisoners [16, 24, 25]. For commercial insurance providers, this may be useful in predicting the budget impact for $\mathrm{HCV}$ or HIV-HCV co-infected patients who are covered by an employer-sponsored plan and may have a different socioeconomic profile compared to a government-sponsored population.

Substance abuse disorders have frequently been cited as potential drivers of morbidity and mortality for patients with HIV and/or HCV infection [26, 27]. Opioid abuse in high-income countries like the US, in particular, has been associated with a higher disease burden related to HIV and HCV [26]. Regardless of the presence of HIV or HCV infection, morbidity and mortality attributed to prescription opioids have increased substantially in the US from 1999 to 2016 [28]. The prevalence of opioid abuse in our cross-sections ranged from $4.5 \%$ to $7.3 \%$ and $7.2 \%$ to $10.8 \%$ for HCV-only and HIV-HCV groups, respectively. 
Table 1 Unadjusted description of three cross-sections by HCV-HIV status

\begin{tabular}{|c|c|c|c|c|c|c|}
\hline & \multicolumn{2}{|l|}{$2007-2009$} & \multicolumn{2}{|l|}{ 2010-2012 } & \multicolumn{2}{|l|}{$2013-2015$} \\
\hline & $\begin{array}{l}\text { HCV-only } \\
(n=21,705) \\
N(\%)\end{array}$ & $\begin{array}{l}\text { HCV-HIV } \\
(n=624) \\
N(\%)\end{array}$ & $\begin{array}{l}\text { HCV-only } \\
(n=22,530) \\
N(\%)\end{array}$ & $\begin{array}{l}\text { HCV-HIV } \\
(n=656) \\
N(\%)\end{array}$ & $\begin{array}{l}\text { HCV-only } \\
(n=26,540) \\
N(\%)\end{array}$ & $\begin{array}{l}\text { HCV-HIV } \\
(n=748) \\
N(\%)\end{array}$ \\
\hline $\begin{array}{l}\text { Age in years } \\
{[\text { mean }(\mathrm{SD})]}\end{array}$ & $47.3(13.3)^{*}$ & $45.5(10.5)^{*}$ & $47.9(14.3)$ & $47.8(10.2)$ & $46.4(16.1)^{*}$ & $47.3(11.5)^{*}$ \\
\hline Male & $12114(55.8)^{*}$ & $451(72.3)^{*}$ & $12383(55.0)^{*}$ & $488(74.4)^{*}$ & $13818(52.1)^{*}$ & $560(74.9)^{*}$ \\
\hline \multicolumn{7}{|c|}{ Potential high cost comorbidities } \\
\hline Cirrhosis & $2972(13.7)$ & $101(16.2)$ & $3233(14.4)$ & $94(14.3)$ & $3374(12.7)$ & $79(10.6)$ \\
\hline $\begin{array}{l}\text { CKD (any } \\
\text { stage) }\end{array}$ & $689(3.2)$ & $26(4.2)$ & $849(3.8)^{*}$ & $47(7.2)^{*}$ & $950(3.6)^{*}$ & $51(6.8)^{*}$ \\
\hline $\mathrm{HBV}$ & $1453(6.7)^{*}$ & $121(19.4)^{*}$ & $1270(5.6)^{*}$ & $74(11.3)^{*}$ & $1088(4.1)^{*}$ & $155(20.7)^{*}$ \\
\hline $\mathrm{HCC}$ & $463(2.1)$ & $10(1.6)$ & $566(2.5)$ & $14(2.1)$ & $569(2.1)$ & $16(2.1)$ \\
\hline $\begin{array}{l}\text { Kidney } \\
\text { transplant }\end{array}$ & $200(0.9)$ & NR & $165(0.7)$ & $5(0.8)$ & $129(0.5)$ & NR \\
\hline $\begin{array}{l}\text { Liver } \\
\text { transplant }\end{array}$ & $397(1.8)^{*}$ & $\mathrm{NR}^{*}$ & $403(1.8)$ & $6(0.9)$ & $378(1.4)$ & $9(1.2)$ \\
\hline $\begin{array}{l}\text { Other } \\
\text { transplant }\end{array}$ & $109(0.5)$ & NR & $93(0.4)$ & NR & $113(0.4)$ & NR \\
\hline \multicolumn{7}{|c|}{ Other comorbidities } \\
\hline CVD & $11,319(52.2)$ & $334(53.5)$ & $11,779(52.3)$ & $363(55.3)$ & $12,621(47.6)$ & $359(48.0)$ \\
\hline Diabetes & $4355(20.1)$ & $140(22.4)$ & $4423(19.6)$ & $131(20.0)$ & $4380(16.5)$ & $139(18.6)$ \\
\hline MDD & $1722(7.9)$ & $59(9.5)$ & $1805(8.0)^{*}$ & $71(10.8)^{*}$ & $2597(9.8)$ & 89 (11.9) \\
\hline Schizophrenia & $177(0.82)$ & $9(1.4)$ & $241(1.1)^{*}$ & $19(2.9)^{*}$ & $242(0.9)^{*}$ & $13(1.7)^{*}$ \\
\hline \multicolumn{7}{|l|}{ Substance abuse } \\
\hline Alcohol & $1738(8.0)^{*}$ & $72(11.5)^{*}$ & $2066(9.2)$ & $66(10.0)$ & $2386(9.0)$ & $80(10.7)$ \\
\hline Cannabis & $274(1.3)$ & $11(1.8)$ & $472(2.1)$ & $20(3.1)$ & $692(2.6)$ & $27(3.6)$ \\
\hline Opioids & $972(4.5)^{*}$ & $45(7.2)^{*}$ & $1438(6.4)^{*}$ & $71(10.8)^{*}$ & $1933(7.3)$ & $59(7.9)$ \\
\hline
\end{tabular}

$N R$ Cell sizes not reported due to small cell sizes $(<5)$, $C K D$ chronic kidney disease, $C V D$ cardiovascular disease, $H B V$ Hepatitis B Virus (); $H C V$ hepatitis $\mathrm{C}$ virus, $H C C$ hepatocellular carcinoma, $H I V$ human immunodeficiency virus, $M D D$ major depressive disorder, $S D$ standard deviation

*Items significantly different $(p$ values $<0.05)$ determined by Chi-square or Fisher's exact test for categorical data, or $t$ test for continuous data

An incremental burden-of-illness study of 20,662 unique $\mathrm{HCV}$ patients matched with non-HCV controls, enrolled primarily in commercial plans from 2002 to 2006 with similar age and sex demographics compared with our study, found similar inpatient, outpatient, and pharmacy proportions after excluding any patients with concurrent HBV [29]. This may 
Table 2 Total unadjusted costs and proportions for each cost category by HCV-HIV status

\begin{tabular}{|c|c|c|c|c|c|c|}
\hline & \multicolumn{2}{|l|}{ 2007-2009 } & \multicolumn{2}{|l|}{ 2010-2012 } & \multicolumn{2}{|l|}{ 2013-2015 } \\
\hline & $\begin{array}{l}\text { HCV-only } \\
(n=21,705)\end{array}$ & $\begin{array}{l}\text { HCV-HIV } \\
(n=624)\end{array}$ & $\begin{array}{l}\text { HCV-only } \\
(n=22,530)\end{array}$ & $\begin{array}{l}\text { HCV-HIV } \\
(n=656)\end{array}$ & $\begin{array}{l}\text { HCV-only } \\
(n=26,540)\end{array}$ & $\begin{array}{l}\text { HCV-HIV } \\
(n=748)\end{array}$ \\
\hline $\begin{array}{l}\text { Total costs during } \\
\operatorname{period}^{\mathrm{a}}(\% \text { of Total })\end{array}$ & $\begin{array}{c}637,426,957 \\
(100.0)\end{array}$ & $\begin{array}{l}45,893,348 \\
\quad(100.0)\end{array}$ & $\begin{array}{c}766,524,750 \\
(100.0)\end{array}$ & $\begin{array}{l}56,682,460 \\
(100.0)\end{array}$ & $\begin{array}{l}1,150,822,687 \\
(100.0)\end{array}$ & $\begin{array}{c}72,333,698 \\
(100.0)\end{array}$ \\
\hline Emergency department & $\begin{array}{l}15,248,889 \\
(2.4)\end{array}$ & $\begin{array}{c}428,146 \\
(0.9)\end{array}$ & $\begin{array}{l}15,861,383 \\
(2.1)\end{array}$ & $\begin{array}{c}629,183 \\
(1.1)\end{array}$ & $\begin{array}{l}19,348,197 \\
(1.7)\end{array}$ & $\begin{array}{c}503,088 \\
(0.7)\end{array}$ \\
\hline Inpatient & $\begin{array}{c}234,719,968 \\
(36.8)\end{array}$ & $\begin{array}{c}8,941,057 \\
(19.5)\end{array}$ & $\begin{array}{c}268,459,457 \\
(35.0)\end{array}$ & $\begin{array}{c}8,779,495 \\
(15.5)\end{array}$ & $\begin{array}{c}351,208,471 \\
(30.5)\end{array}$ & $\begin{array}{c}12,876,517 \\
(17.8)\end{array}$ \\
\hline Outpatient & $\begin{array}{l}213,541,522 \\
\quad(33.5)\end{array}$ & $\begin{array}{c}6,519,325 \\
(14.2)\end{array}$ & $\begin{array}{l}263,578,469 \\
(34.4)\end{array}$ & $\begin{array}{c}9,680,188 \\
(17.1)\end{array}$ & $\begin{array}{c}326,351,253 \\
(28.4)\end{array}$ & $\begin{array}{c}8,633,675 \\
(11.9)\end{array}$ \\
\hline Pharmacy & $\begin{array}{c}125,271,079 \\
(19.7)\end{array}$ & $\begin{array}{c}20,969,694 \\
(45.7)\end{array}$ & $\begin{array}{c}143,336,761 \\
(18.7)\end{array}$ & $\begin{array}{c}23,423,862 \\
(41.3)\end{array}$ & $\begin{array}{c}389,920,929 \\
(33.9)\end{array}$ & $\begin{array}{c}40,191,758 \\
(55.6)\end{array}$ \\
\hline Other & $\begin{array}{c}6,786,879 \\
(1.1)\end{array}$ & $\begin{array}{c}249,131 \\
(0.5)\end{array}$ & $\begin{array}{l}11,946,712 \\
(1.6)\end{array}$ & $\begin{array}{c}497,641 \\
(0.9)\end{array}$ & $\begin{array}{l}17,907,053 \\
(1.6)\end{array}$ & $\begin{array}{c}1,333,542 \\
(1.8)\end{array}$ \\
\hline Unknown & $\begin{array}{l}41,858,620 \\
(6.6)\end{array}$ & $\begin{array}{c}8,785,995 \\
(19.1)\end{array}$ & $\begin{array}{l}63,341,968 \\
(8.3)\end{array}$ & $\begin{array}{c}13,672,091 \\
(24.1)\end{array}$ & $\begin{array}{l}46,086,784 \\
(4.0)\end{array}$ & $\begin{array}{c}8,795,118 \\
(12.2)\end{array}$ \\
\hline
\end{tabular}

$H C V$ hepatitis $\mathrm{C}$ virus, $H I V$ human immunodeficiency virus

a In US Dollars adjusted to the end of each period (2009, 2012, and 2015)

have limited the number of HIV-HCV co-infected patients included in the study as we identified a higher prevalence of HBV in the coinfected group. McAdam-Marx et al. evaluated all-cause and incremental per patient per year costs associated with chronic HCV in a large commercial insurance database from 2001 to 2010 [21]. They estimated inpatient, outpatient, emergency room, and pharmacy costs were $27 \%, 46 \%, 0.5 \%$, and $27 \%$ of total costs, respectively [21]. In this study, we identified an increase in the proportion of total health care costs attributed to total pharmacy claims in both HIV-HCV and HCV-only groups after 2012. This coincides with the approval of newer DAA treatments for chronic HCV. McAdamMarx et al. also estimated annual spending at $\$ 19,660$ for chronic HCV patients, which was less than our estimates for HCV-only $(\$ 29,368$ from 2007 to 2009; $\$ 34,022$ from 2010 to 2012; and $\$ 43,362$ from 2013 to 2015) [21]. This may reflect the matching methods and incremental costing approach used in that study, in addition to the increasing cost and changing treatment with newer therapies. When combined inpatient/outpatient medical costs for HCV-only patients are considered, our 2007-2009 (70\%) and 2010-2012 (69\%) cross-sections were very similar to the McAdam-Marx study (73\%), while the 2013-2015 HCV-only group inpatient/outpatient spend was just 58\% of total costs. This demonstrates a potential shift in burden to the pharmacy benefit, but not necessarily a saving in other areas as overall spending increases. Reduced spending on liverrelated morbidity may not be observed for years after HCV treatment.

\section{Limitations}

First, this study was designed as a descriptive total cost analysis whereby results should be interpreted as a representation of the data analyzed and not extrapolated or applied to other 

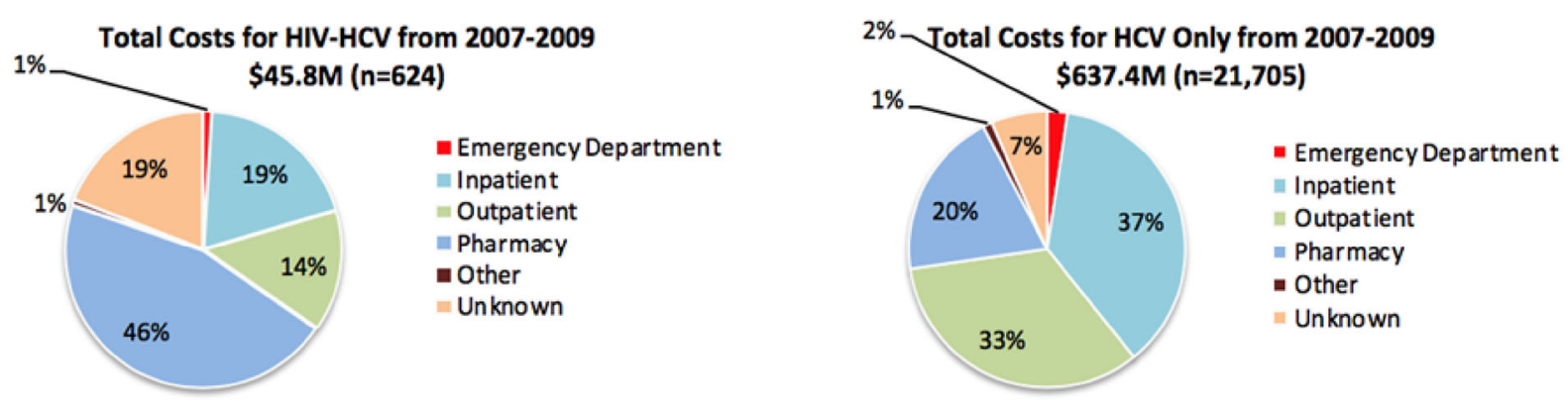

Total Costs for HIV-HCV from 2010-2012 $\$ 56.7 \mathrm{M}(\mathrm{n}=656)$

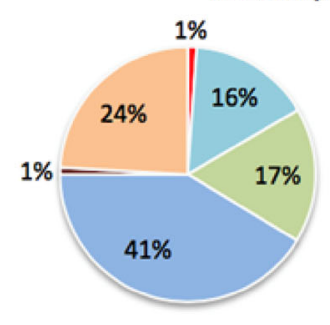

- Emergency Department

$=$ Inpatient

Outpatient

= Pharmacy

- Other

Unknown

Total Costs for HIV-HCV from 2013-2015

$\$ 72.3 M(n=748)$

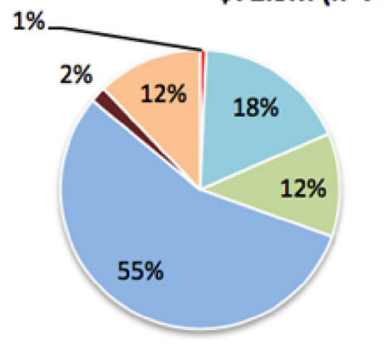

- Emergency Department
$=$ Inpatient
= Outpatient
= Pharmacy
= Other
= Unknown

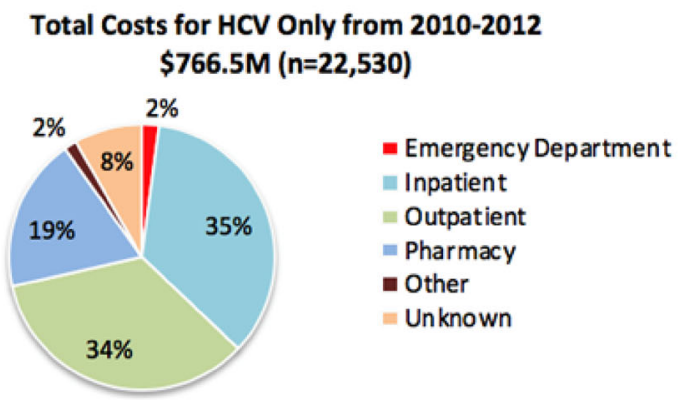

Total Costs for HCV Only from 2013-2015

\$1.15B $(n=26,540)$

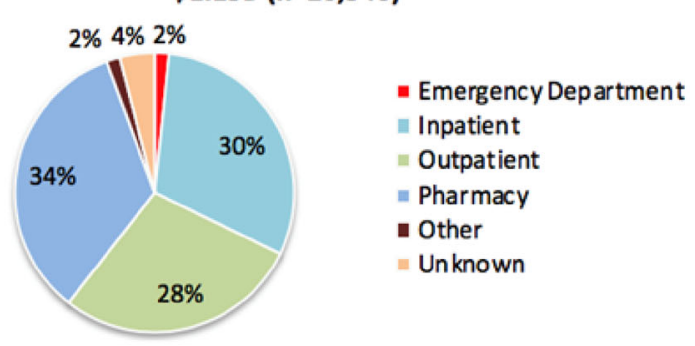

Fig. 1 Total costs for all three cross-sections by HIV-HCV status and cost category

populations. By reporting these observations in a commercially insured sample, future researchers could consider potential differences in the prevalence of comorbidities and total costs that may better inform the methodological approach during the design of an economic model or real-world observational analysis. Additionally, these results represent a 10\% random sample from the commercially insured US population covered by the IQVIA ${ }^{\mathrm{TM}}$ dataset. Cost data may be skewed and potentially bimodal (with a high proportion of patients with zero utilization), so the ability to scale these results to a larger population may be limited. Future studies with financial support to purchase the full dataset would be warranted to confirm these prevalences and cost estimates.

The identification of HCV-only and HIVHCV patients was reliant on ICD-9 and ICD-10 diagnosis coding observed in claims during the cross-sectional period, which could have led to misclassification of disease from coding errors or omissions. Additionally, patients were flagged to HCV-only and HIV-HCV groups if they met the criteria within the 3-year cross-section. This may have led to additional misclassification for a patient who was truly HIV-only or HCV-only at the beginning of the observation period, but categorized as an HIV-HCV coinfected patient based on a later claim. To 
reduce this potential bias, we divided the larger 2007-2015 cohort into three separate crosssections for study inclusion and analysis.

A total cost approach for cost-of-illness research describes the prevalence and reports of what was spent on claims for a given time period. By reporting total costs without statistical techniques to address underlying differences between the groups, we were unable to make a causal argument for the cost difference observed. The total cost approach was used for this study for its advantages in interpretation and relevance to decision-makers or payers who are responsible for all direct healthcare costs for patients enrolled. All comorbidities were also dependent on diagnosis coding. This is particularly problematic for diseases that may be under-diagnosed, such as the psychiatric diseases and substance abuse variables in our analysis. Other studies that use a different approach that captures a broader definition of substance use in addition to medically diagnosed abuse may identify many more cases.

This study was also limited by the ability to categorize claims in cases where the data vendor masked the place of service code. Unknown place of service claims represented between $4 \%$ and $8 \%$ of claims in the HCV-only group and between $12 \%$ and $24 \%$ in the HIV-HCV group. This may underrepresent the proportion of spending in other categories, but would not change the qualitative interpretation of the increase due to pharmacy costs for either group.

\section{CONCLUSION}

The present study describes the prevalence of multiple comorbidities and total direct health care costs in HIV-HCV co-infected individuals and HCV-only patients in commercially insured health plans. Spending on pharmacy increased as a proportion of total health care costs in both groups. Further clinical and economic evaluations in HCV and/or HIV populations in the US should consider system-level factors related to insurance type when applying to the entire population.

\section{ACKNOWLEDGEMENTS}

The authors would like to acknowledge the staff of Pharmaceutical Research Computing (PRC), University of Maryland Baltimore for their analytical and programming support. A list of the current staff is available on the PRC web site at http://www.pharmacy.umaryland.edu/ centers/prc/staff.html. The statements, findings, conclusions, views, and opinions contained and expressed in this article are based in part on data obtained under license from the IQVIA $^{\mathrm{TM}}$ information service: IQVIA $^{\mathrm{TM}}$ PharMetrics Plus adjudicated claims database, 2007-2015. All Rights Reserved. The statements, findings, conclusions, views, and opinions contained and expressed herein are not necessarily those of IQVIA ${ }^{\mathrm{TM}}$ or any of its affiliated or subsidiary entities.

Funding. T. Joseph Mattingly II and Neha S. Pandit received an internal research award to conduct this analysis. The funding provided access to the dataset, data cleaning, and coding support from Pharmaceutical Research Computing (a center within the University of Maryland School of Pharmacy's Department of Pharmaceutical Health Services Research). The article processing charges were funded by the authors.

Authorship. All named authors meet the International Committee of Medical Journal Editors (ICMJE) criteria for authorship for this article, take responsibility for the integrity of the work as a whole, and have given their approval for this version to be published.

Disclosures. T. Joseph Mattingly II reports advisory board and consulting fees from G\&W Laboratories, American Pharmacists Association, National Health Council, Paratek Pharmaceuticals, and Summit Therapeutics and reports educational grants from Bristol-Myers Squibb, ALK Abello, and the Patient Centered Outcomes Research Institute for unrelated work. Neha S. Pandit and Eberechukwu Onukwugha have nothing to disclose. 
Compliance with Ethics Guidelines. This article does not contain any studies with human participants or animals performed by any of the authors and the study protocol was reviewed and approved as "Not Human Subjects Research" by the University of Maryland, Baltimore Institutional Review Board on May 10, 2018 .

Data Availability. Data used in this analysis was obtained under a data use agreement between the University of Maryland and IQVIA $^{\mathrm{TM}}$. Any requests for access to this data must be made to IQVIA ${ }^{\mathrm{TM}}$.

Open Access. This article is distributed under the terms of the Creative Commons Attribution-NonCommercial 4.0 International License (http://creativecommons.org/licenses/ by-nc/4.0/), which permits any noncommercial use, distribution, and reproduction in any medium, provided you give appropriate credit to the original author(s) and the source, provide a link to the Creative Commons license, and indicate if changes were made.

\section{REFERENCES}

1. Clausen LN, Lundbo LF, Benfield T. Hepatitis C virus infection in the human immunodeficiency virus infected patient. World J Gastroenterol. 2014;20:12132-43.

2. Linas BP, Barter DM, Leff JA, et al. The cost-effectiveness of improved hepatitis $\mathrm{C}$ virus therapies in HIV/hepatitis C virus coinfected patients. AIDS. 2014;28:365-76.

3. Hadigan C, Kottilil S. Hepatitis C virus infection and coinfection with human immunodeficiency virus. JAMA. 2011;306:294-301.

4. Heil EL, Hynicka LM, Kottilil S, Tang L. What does the pharmacological future of treating chronic hepatitis C look like? Expert Rev Clin Pharmacol. 2015;8:1-18.

5. Naggie S, Cooper C, Saag M, et al. Ledipasvir and sofosbuvir for HCV in patients coinfected with HIV1. N Engl J Med. 2015;373:705-13.

6. Saab S, Gordon SC, Park H, Sulkowski M, Ahmed A, Younossi Z (2014) Cost-effectiveness analysis of sofosbuvir plus peginterferon/ribavirin in the treatment of chronic hepatitis $\mathrm{C}$ virus genotype 1 infection. Aliment Pharmacol Ther. https://doi.org/ 10.1111/apt.12871.

7. Sublette VA, Smith SK, George J, McCaffery K, Douglas MW. The Hepatitis $\mathrm{C}$ treatment experience: patients' perceptions of the facilitators of and barriers to uptake, adherence and completion. Psychol Health. 2015;30:987-1004.

8. Barua S, Greenwald R, Grebely J, Dore GJ, Swan T, Taylor LE. Restrictions for medicaid reimbursement of sofosbuvir for the treatment of hepatitis $C$ virus infection in the United States. Ann Intern Med. 2015;163:215-23.

9. Do A, Mittal Y, Liapakis A, et al. Drug authorization for sofosbuvir/ledipasvir (harvoni) for chronic HCV infection in a real-world cohort: a new barrier in the HCV care cascade. PLoS ONE. 2015;10:1-15.

10. Fleming CA, Craven DE, Thornton D, Tumilty S, Nunes D. Hepatitis C virus and human immunodeficiency virus coinfection in an urban population: low eligibility for interferon treatment. Clin Infect Dis. 2003;36:97-100.

11. Rice DP. Estimating the cost of illness. Am J Public Health. 1967;57:424-40.

12. Akobundu E, Ju J, Blatt L, Mullins CD. Cost-of-illness studies: a review of current methods. Pharmacoeconomics. 2006;24:869-90.

13. Onukwugha E, McRae J, Kravetz A, Varga S, Khairnar R, Mullins CD. Cost-of-illness studies: an updated review of current methods. Pharmacoeconomics. 2015;34:43-58.

14. Pham TT, Keast SL, Farmer KC, Thompson DM, Rathbun RC, Nesser NJ, Holderread BP, Skrepnek $\mathrm{GH}$. Sustained virologic response and costs associated with direct-acting antivirals for chronic hepatitis c infection in oklahoma medicaid. J Manag Care Spec Pharm. 2018;24:664-76.

15. Belperio PS, Backus LI, Ross D, Neuhauser MM, Mole LA. A population approach to disease management: hepatitis $\mathrm{C}$ direct-acting antiviral use in a large health care system. J Manag Care Pharm. 2014;20:533-40.

16. Katrak S, Park LP, Woods C, Muir A, Hicks C, Naggie $S$. Patterns of healthcare utilization among veterans infected with Hepatitis $\mathrm{C}$ virus (HCV) and human immunodeficiency virus (HIV) and coinfected with $\mathrm{HIV} / \mathrm{HCV}$ : unique burdens of disease. Open Forum Infect Dis. 2016;3:1-8.

17. Hammett TM, Harmon MP, Rhodes W. The burden of infectious disease among inmates of and 
releasees from US correctional facilities, 1997. Am J Public Health. 2002;92:1789-94.

18. Norton BL, Park L, McGrath LJ, Proeschold Bell RJ, Muir AJ, Naggie S. Health care utilization in HIVinfected patients: assessing the burden of hepatitis C virus coinfection. AIDS Patient Care STDS. 2012;26:541-5.

19. Alcala HE, Roby DH, Grande DT, McKenna RM, Ortega AN. Insurance type and access to health care providers and appointments under the affordable care act. Med Care. 2018;56:186-92.

20. El Khoury AC, Klimack WK, Wallace C, Razavi H. Economic burden of hepatitis C-associated diseases in the United States. J Viral Hepat. 2012;19:153-60.

21. McAdam-Marx C, McGarry LJ, Hane CA, Biskupiak J, Deniz B, Brixner DI. All-cause and incremental per patient per year cost associated with chronic hepatitis $C$ virus and associated liver complications in the United States: a managed care perspective. J Manag Care Pharm. 2011;17:531-46.

22. Sanders GD, Neumann PJ, Basu A, et al. Recommendations for conduct, methodological practices, and reporting of cost-effectiveness analyses. JAMA. 2016;316:1093-103.

23. Dunn A, Grosse SD, Zuvekas SH. Adjusting health expenditures for inflation: a review of measures for health services research in the United States. Health Serv Res. 2018;53:175-96.
24. Clements KM, Clark RE, Lavitas P, Kunte P, Graham CS, O'Connell E, Lenz K, Jeffrey P. Access to new medications for hepatitis $C$ for medicaid members: a retrospective cohort study. J Manag Care Spec Pharm. 2016;22:714-722b.

25. Weinbaum C, Sabin K, Santibanez S. Hepatitis B, hepatitis C, and HIV in correctional populations: a review of epidemiology and prevention. AIDS. 2005;19:41-6.

26. Degenhardt L, Hall W. Extent of illicit drug use and dependence, and their contribution to the global burden of disease. Lancet. 2012;379:55-70.

27. Innes $\mathrm{H}$, McAuley $\mathrm{A}$, Alavi $\mathrm{M}$, Valerio $\mathrm{H}$, Goldberg D, Hutchinson SJ. The contribution of health risk behaviors to excess mortality in American adults with chronic hepatitis C: a population cohortstudy. Hepatology. 2018;67:97-107.

28. Jalal H, Buchanich JM, Roberts MS, Balmert LC, Zhang K, Burke DS (2018) Changing dynamics of the drug overdose epidemic in the United States from 1979 through 2016. Science (80-). https://doi. org/10.1126/science.aau1184.

29. Davis KL, Mitra D, Medjedovic J, Beam C, Rustgi V. Direct economic burden of chronic hepatitis $C$ virus in a United States managed care population. J Clin Gastroenterol. 2011;45:e17-24. 